Гвоздев М.А. ${ }^{1}$, Кондратьев А.В. ${ }^{2}$

${ }^{1}$ Государственное предприятие «АНТОНОВ». Украина, г. Киев

${ }^{2}$ Национальный аэрокосмический университет им. Н.Е. Жуковского «ХАИ». Украина, г. Харьков

\title{
ПРОГНОЗИРОВАНИЕ ТЕХНИЧЕСКИ ВОЗМОЖНОГО ОБЪЕМА ВНЕДРЕНИЯ ПОЛИМЕРНЫХ КОМПОЗИЦИОННЫХ МАТЕРИАЛОВ В КОНСТРУКЦИЯХ САМОЛЕТОВ
}

Предложен общий статистический подход к прогнозированию технически возможного объема внедрения полимерных композиционных материалов в конструкциях летательных аппаратов. Дальнейшая углубленная разработка предложенного статистического подхода может быть положена в основу синтеза научных основ прогнозирования внедрения полимерных композиционных материалов в конструкциях летательных аппаратов как краткосрочного, так и перспективного периодов с учетом различных определяющих факторов отечественного развития отрасли.

Ключевые слова: летательные аппараты; полимерные композиционные материалы; прогнозирование; статистический подход.

\section{Состояние проблемы}

Одним из общепризнанных путей дальнейшего повышения эффективности самолетов как гражданской, так и военной авиации является перманентное увеличение объема применения в их конструкциях полимерных композиционных материалов (ПКМ) [1-5].

Начавшееся более полувека тому назад внедрение ПКМ в авиастроение прошло непростой путь все расширяющейся области замены традиционных металлов композитами от узлов и агрегатов, не определяющих несущую способность самолета (не нагруженных и слабо нагруженных) до основных агрегатов: крыла, фюзеляжа, оперения [6-8].

В научных публикациях все чаще обсуждается возможность максимальной замены металлов композитами как экономически оправданной, так и технически реализуемой в разных странах для различных классов самолетов [9].

Относительно строгое решение этой многоаспектной проблемы, по-видимому, является недо- стижимым, во всяком случае, в настоящее время и в ближайшем будущем.

Однако представляется оправданным обсудить один из путей прогнозирования технически возможного (максимального) объема внедрения ПКМ в конструкциях самолетов практически любого класса, не затрагивающих экономической целесообразности этой проблемы.

\section{Анализ проблемы}

Мировая статистика располагает достаточно узкими диапазонами изменения массы конструкции каждого класса самолета $m_{\mathrm{k}}$, отнесенной к его взлетной массе $m_{0}$ :

$$
\bar{m}_{\mathrm{r}}=\frac{m_{\mathrm{r}}}{m_{0}} .
$$

Так, например, в [10] приведены статистические значения относительных масс конструкции и других групп весовой классификации самолетов транспортной категории (табл. 1).

Таблица 1

Статистические значения относительных масс конструкции, силовой установки, оборудования и управления, а также топлива самолетов транспортной категории

\begin{tabular}{|c|c|c|c|c|c|}
\hline \multicolumn{2}{|c|}{ Назначение самолета } & $\overline{\boldsymbol{m}}_{\text {к }}$ & $\overline{\boldsymbol{m}}_{\text {c.y }}$ & $\overline{\boldsymbol{m}}_{\text {об.ушр }}$ & $\overline{\boldsymbol{m}}_{\text {т }}$ \\
\hline Дозвуковые & Легкие & $0,30 \ldots 0,32$ & $0,12 \ldots ., 14$ & $0,12 \ldots . .14$ & $0,18 \ldots ., 22$ \\
пассажирские & средние & $0,28 \ldots 0,30$ & $0,10 \ldots 0,12$ & $0,10 \ldots 0,12$ & $0,26 \ldots 0,30$ \\
магистральные & тяжелые & $0,25 \ldots 0,27$ & $0,08 \ldots 0,10$ & $0,09 \ldots 0,11$ & $0,35 \ldots 0,40$ \\
\hline \multicolumn{2}{|c|}{ Многоцелевые для местных } \\
авиалиний
\end{tabular}


В [11] для дальних магистральных пассажирских самолетов приведена относительная маса конструкции $\bar{m}_{\mathrm{K}}=0,23 \ldots 0,28$.

Аналогичные данные для более широкого класса самолетов приведены в табл. 2 [12], в [13] дана массо- вая сводка по структурным группам самолетов различных классов. Состав массы основных структурных элементов самолета представлен в табл. 3-6 [12].

К группе «конструкция самолетов» относятся [12]:

- крыло с герметизацией топливных отсеков;

Таблица 2

Относительные массы конструкции, силовой установки, оборудования и управления, а также топлива самолетов с обычным взлетом и посадкой

\begin{tabular}{|c|c|c|c|c|c|}
\hline \multicolumn{2}{|c|}{ Назначение самолета } & $\overline{\boldsymbol{m}}_{\mathrm{\kappa}}$ & $\overline{\boldsymbol{m}}_{\mathrm{c.y}}$ & $\overline{\boldsymbol{m}}_{\text {об.улір }}$ & $\overline{\boldsymbol{m}}_{\mathrm{r}}$ \\
\hline \multicolumn{2}{|c|}{ Сверхзвуковые пассажирские } & $0,20 \ldots 0,24$ & $0,08 \ldots 0,10$ & $0,07 \ldots 0,09$ & $0,45 \ldots 0,52$ \\
\hline \multicolumn{2}{|l|}{ Спортивно-пилотажные } & $0,32 \ldots 0,34$ & $0,26 \ldots 0,30$ & $0,06 \ldots 0,07$ & $0,10 \ldots 0,15$ \\
\hline \multicolumn{2}{|l|}{$\begin{array}{l}\text { Сельскохозяйственные } \\
\text { специализированные }\end{array}$} & $0,24 \ldots 0,30$ & $0,12 \ldots 0,15$ & $0,12 \ldots 0,15$ & $0,08 \ldots 0,12$ \\
\hline \multicolumn{2}{|l|}{ Легкие гидросамолеты } & $0,34 \ldots 0,38$ & $0,12 \ldots 0,15$ & $0,12 \ldots 0,15$ & $0,10 \ldots 0,20$ \\
\hline \multicolumn{2}{|l|}{ Мотопланеры } & $0,48 \ldots 0,52$ & $0,08 \ldots 0,10$ & $0,06 \ldots 0,08$ & $0,08 \ldots 0,12$ \\
\hline \multicolumn{2}{|l|}{ Истребители } & $0,28 \ldots 0,32$ & $0,18 \ldots 0,22$ & $0,12 \ldots 0,14$ & $0,25 \ldots 0,30$ \\
\hline Бомбардировщики & $\begin{array}{c}\text { легкие } \\
\text { средние } \\
\text { тяжелые }\end{array}$ & $\begin{array}{l}0,26 \ldots 0,28 \\
0,22 \ldots 0,24 \\
0,18 \ldots 0,20\end{array}$ & $\begin{array}{l}0,10 \ldots 0,12 \\
0,08 \ldots 0,10 \\
0,06 \ldots 0,08\end{array}$ & $\begin{array}{l}0,10 \ldots 0,12 \\
0,07 \ldots 0,10 \\
0,06 \ldots 0,08\end{array}$ & $\begin{array}{l}0,35 \ldots 0,40 \\
0,45 \ldots 0,50 \\
0,55 \ldots 0,60\end{array}$ \\
\hline $\begin{array}{l}\text { Военно-транспортные } \\
\text { и грузовые }\end{array}$ & $\begin{array}{c}\text { легкие } \\
\text { средние } \\
\text { тяжелые }\end{array}$ & $\begin{array}{l}0,30 \ldots 0,32 \\
0,26 \ldots 0,28 \\
0,28 \ldots 0,32\end{array}$ & $\begin{array}{l}0,12 \ldots 0,14 \\
0,10 \ldots 0,12 \\
0,08 \ldots 0,10\end{array}$ & $\begin{array}{l}0,16 \ldots 0,18 \\
0,12 \ldots 0,14 \\
0,06 \ldots 0,08\end{array}$ & $\begin{array}{c}0,2 \ldots 0,25 \\
0,25 \ldots 0,30 \\
0,30 \ldots 0,35\end{array}$ \\
\hline
\end{tabular}

Таблица 3

Состав массы крыла по элементам (\%)

\begin{tabular}{|l|c|c|}
\hline \multicolumn{1}{|c|}{ Элементы } & Лонжеронное крыло & Кесонное крыло \\
\hline $\begin{array}{l}\text { Силовая и несиловая обшивки } \\
\text { (без элеронов и механизации) }\end{array}$ & $35 \ldots 40$ & $27 . \ldots 32$ \\
\hline Лонжероны (стенки) & $23 \ldots 28$ & $7 \ldots 11$ \\
\hline Стрингеры & $4 \ldots 8$ & $25 \ldots 30$ \\
\hline Нервюры & $8 \ldots 10$ & $8 \ldots 12$ \\
\hline Узлы, стыки & $3 \ldots 4$ & $6 \ldots 8$ \\
\hline $\begin{array}{l}\text { Элероны, закрылки, } \\
\text { предкрылки, интерцепторы }\end{array}$ & $10 \ldots 15$ & $10 \ldots 15$ \\
\hline Крепеж и прочее & $4 \ldots 6$ & $4 \ldots 6$ \\
\hline
\end{tabular}

Таблица 4

Состав массы фюзеляжа по элементам (\%)

\begin{tabular}{|c|c|c|}
\hline Элементы & $\begin{array}{c}\text { Легкие самолеты } \\
\lambda_{\phi}=6 \ldots 8\end{array}$ & $\begin{array}{c}\text { Тяжелые самолеты } \\
\lambda_{\phi}=9 . . .12\end{array}$ \\
\hline Обшивка & $25 \ldots 30$ & $25 \ldots 30$ \\
\hline Стрингеры и лонжероны & $12 \ldots 15$ & $15 \ldots 20$ \\
\hline Шпангоуты & $20 \ldots 25$ & $22 \ldots 27$ \\
\hline Полы & $6 \ldots 9$ & $8 \ldots 12$ \\
\hline Фонарь пилотов & $10 \ldots 12$ & $2 \ldots 3$ \\
\hline Окна пассажирской кабины & $3 \ldots 5$ & $4 \ldots 5$ \\
\hline Двери, трапы, люки & $6 \ldots 8$ & $3 \ldots 4$ \\
\hline Прочее (перегородки, соединения, герметизация, крепеж) & $7 \ldots 9$ & $9 \ldots 11$ \\
\hline
\end{tabular}




\section{Состав массы оперения по элементам (\%)}

\begin{tabular}{|c|c|c|}
\hline Элементы & $m_{0} \leq 7 \cdot 10^{3}$ кг & $m_{0}>10^{3}$ кг \\
\hline $\begin{array}{l}\text { Стабилизатор и киль: } \\
\text { лонжероны и стрингеры } \\
\text { обшивка } \\
\text { нервюры } \\
\text { узлы крепления } \\
\end{array}$ & $\begin{array}{c}25 \ldots 30 \\
30 \ldots 35 \\
5 \ldots 7 \\
2 \ldots 3\end{array}$ & $\begin{array}{c}25 \ldots 30 \\
32 \ldots 37 \\
9 \ldots 12 \\
6 \ldots 8 \\
\end{array}$ \\
\hline Рули с балансирами, триммерами, узлами подвески и др. & $20 \ldots 25$ & $15 \ldots 18$ \\
\hline Прочее (законцовки, крепеж, детали крепления оборудования. & $6 \ldots 10$ & $3 \ldots 6$ \\
\hline
\end{tabular}

Состав массы шасси по элементам (\%)

\begin{tabular}{|c|c|c|c|}
\hline \multirow[b]{2}{*}{ Элементы } & \multicolumn{2}{|c|}{ Главные стойки } & \multirow[b]{2}{*}{ Носовая стойка } \\
\hline & $\begin{array}{c}\text { С двумя } \\
\text { колесами }\end{array}$ & $\begin{array}{l}\text { С четырех- } \\
\text { колесной } \\
\text { тележкой }\end{array}$ & \\
\hline Колеса & $55 \ldots 60$ & $45 \ldots 50$ & $20 \ldots 25$ \\
\hline Амортизационные стойки с шлицшарнирами & $14 \ldots 16$ & $16 \ldots 19$ & $20 \ldots 25$ \\
\hline Детали тележки, оси колес & $3 \ldots 4$ & $9 \ldots 11$ & $3 \ldots 4$ \\
\hline $\begin{array}{l}\text { Кинематические детали и механизмы, замки, } \\
\text { детали управления и автоматики }\end{array}$ & $20 \ldots 24$ & $20 \ldots 24$ & $45 \ldots 48$ \\
\hline Створки с управлением и прочее & $2 \ldots 3$ & $2 \ldots 3$ & $2 \ldots 3$ \\
\hline $\begin{array}{l}\text { - фюзеляж, включая тормозные аэродинал } \\
\text { ские щитки, полы и перегородки, герметиз } \\
\text { отсеков; }\end{array}$ & & $\begin{array}{l}V_{\text {мет }}>V_{\text {II }} \\
V_{\text {мет }} \leq V_{\text {II }}\end{array}$ & $(5)$ \\
\hline
\end{tabular}

- оперение, включая форкиль, гребни и шайбы;

- взлетно-посадочные устройства (шасси) со створками и цилиндрами уборки-выпуска шасси, обтекатели шасси, тормозные парашюты;

- окраска поверхности самолета.

\section{Решение проблемы}

В общем случае диапазон изменения относительной массы конструкции самолета

$$
\bar{m}_{\mathrm{K}_{\min }} \leq \bar{m}_{\mathrm{K}} \leq \bar{m}_{\mathrm{x}_{\max }} .
$$

При этом массы конструкции самолета из металлов и из ПКМ соответственно равны:

$$
\begin{gathered}
m_{\text {к мет }}=\rho_{\text {мет }} \cdot V_{\text {мег }} ; \\
m_{\text {кПКм }}=\rho_{\text {ПКм }} \cdot V_{\text {ПКм }} \cdot
\end{gathered}
$$

Здесь $\rho_{\text {мет}}, \rho_{\text {пКм }}-$ плотность металла и ПКМ соответственно; $V_{\text {мет}}, V_{\text {Пкм }}-$ физический объем металла и ПКМ в конструкции самолета.

Теоретически в общем случае возможны варианты соотношений объемов:

Таблица 6

Поэтому исходя из неравенств (5)-(6) можно принять, что

$$
V_{\text {ПКм }}=\xi V_{\text {мет }},
$$

где $\xi$ - принимаемый известным коэффициент изменения объема в конструкции самолета из ПКМ по сравнению с металлической.

С учетом (7) и соотношений $V_{\text {мет }}=\frac{m_{\text {кмет }}}{\rho_{\text {мет }}}$, $V_{\text {Пкм }}=\frac{m_{\text {кпкм }}}{\rho_{\text {пкм }}}$ получим

$$
\frac{m_{\text {кпКм }}}{\rho_{\text {пКм }}}=\xi \frac{m_{\text {кмет }}}{\rho_{\text {мет }}}
$$

или

$$
\bar{m}_{\text {кпКм }}=\xi \frac{\rho_{\text {ПКК }}}{\rho_{\text {мет }}} \bar{m}_{\text {кмет }} \text {. }
$$

В настоящее время основными ПКМ, используемыми в конструкциях самолета являются стек- 
Диапазоны плотностей полимерных композиционных материалов

\begin{tabular}{|c|c|c|c|}
\hline $\begin{array}{c}\text { № } \\
\text { II/I }\end{array}$ & Тип ПКМ & Плотность $\rho \cdot 10^{-3}$, кг $/ \mathrm{m}^{3}$ & $\max$ \\
\hline 1 & стеклопластики & $1,9 \ldots 2,2[15] ; 1,5 \ldots 1,9[17] ; 1,65 \ldots 1,95[16]$ & 2,2 \\
\hline 2 & углепластики & $1,4 \ldots 1,55[17] ; 1,3 \ldots 1,57[15] ; 1,36 \ldots 1,55[16]$ & 1,57 \\
\hline 3 & органопластики & $1,33 \ldots 1,35[17] ; 1,3 \ldots 1,38[15] ; 1,17 \ldots 1,4[16]$ & 1,4 \\
\hline
\end{tabular}

лопластики, углепластики и органопластики, диапазоны плотностей которых приведены в табл. 7.

Как видно из табл. 7, диапазоны плотностей ПКМ разных типов согласно вызывающих доверие справочникам близки. Однако для дальнейшего использования в предлагаемой методике прогнозирования, повидимому, следует ориентироваться на максимальные значения плотности, указанные в таблице, которым соответствуют ПКМ с наилучшими физикомеханическими и прочностными характеристиками.

В формуле (9) $\bar{m}_{\text {кмет }}$ всегда меньше определяемой формулами (1) и (2), так как полностью заменить всю металлическую конструкцию самолета на композитную принципиально невозможно: всегда останутся металлические стыковые узлы, соединения, значительная часть крепежа, детали шасси и т.д. Поэтому на основе экспертных оценок может быть установлен коэффициент, определяющий предельно допустимую часть заменяемой относительной массы металлической конструкции $\varphi<1$. Кроме того, в различных агрегатах металлической конструкции самолета применяются три основных металлических сплава: алюминиевых, титановых и стали, доля каждого из которых, отнесенная к базовому (превалирующим алюминиевым сплавам), составляет коэффициенты, также определяемые экспертным путем: для титановых сплавов $K_{T i}=\frac{m_{\text {кті }}}{\bar{m}_{\text {к Al }}}$, для стальных конструктивных элементов $K_{\text {ст }}=\frac{m_{\text {кст }}}{\bar{m}_{\text {к Al }}}$.

Аналогично для замены металла применяют также три основных типа ПКМ, приведенные в табл. 7.

Соответственно на основе опыта применения того или иного типа ПКМ в отечественном самолетостроении и с учетом мировых тенденций вместо $\rho_{\text {пкм }}$ в формуле (9) следует ввести коэффициенты, определяющие доли применения: стеклопластика, отнесенного к доли превалирующего согласно мировому и отечественному опыту углепластика и доли органопластика $K_{\text {орг }}$, также отнесенной к доли углепластика.

В результате таких преобразований вместо формулы (9) получим

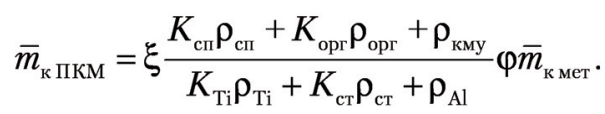

Определив $\bar{m}_{\text {к пкм из }}$ (10) и воспользовавшись (1), найдем абсолютную массу замененной части металлической конструкции

$$
\bar{m}_{\text {кмет }}=m_{0} \cdot \bar{m}_{\text {к }}
$$

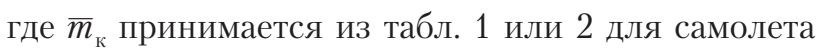
массой $m_{0}$, для которого прогнозируется эффективность замены металла на ПКМ, определяемая как отношение $\frac{m_{\text {кпкм }}}{m_{\text {кмет }}} 100 \%$.

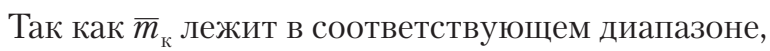
то, воспользовавшись его граничными значениями, можно установить «вилку» снижения массы, определяющую «оптимистичный» и «пессимистичный» прогнозы.

В качестве примера рассмотрим прогнозирование снижения массы самолета Ан-178 со взлетной массой $m_{0}=52$ т, относя его к диапазону $0,28 \leq \bar{m}_{\mathrm{\kappa}}<0,3$ табл. 1 и значениях параметров, входящих в (11), приблизительно соответствующих современному уровню применяемых на ГП «Антонов»: $\xi=0,8$; $\varphi=0,75 ; K_{\text {сп }}=0,3 ; K_{\text {орг }}=0,1 ; K_{\mathrm{Ti}}=0,2 ; K_{\text {ст }}=0,2$.

Подставив эти значения в (11), получим при $\bar{m}_{\text {к }}=0,3, \bar{m}_{\text {к пкм }}=0,085$ и $m_{\text {к Кпм }}=0,085 \cdot 52=4,42$ т. Соответственно $m_{\text {кмет }}=52 \cdot 0,3=15,6$ т. Снижение массы составит $\frac{m_{\text {кпКм }}}{m_{\text {кмет }}} 100 \%=28,3 \%$.

При $\bar{m}_{\text {к }}=0,28$ это снижение будет равно $30,3 \%$ и составит 4,16 т.

Результаты прогнозирования в приведенном выше примере являются виртуальными, т.к. указанные в нем параметры в настоящее время могут существенно отличаться в силу имеющих место технических, экономических, политических и других факторов, динамика изменения которых должна учитываться при реальном прогнозировании.

\section{Выводы}

1. Предложенный статистический подход к прогнозированию технически возможного объема внедрения ПКМ в конструкциях самолетов, несомненно, дает результат первого приближения, на который может ориентироваться разработчик того или иного 
класса самолетов, ориентированных на изготовление во вполне определенных производственно-технических условиях и располагаемых ресурсах.

2. Ожидаемая точность прогноза в большой, если не определяющей степени зависит от обоснованности и достоверности выбора параметров, входящих в зависимость (10), но в то же время результат прогноза может продуктивно корректироваться введением соответствующих уточняющих поправок во вводимые параметры, учитывающих экономические, политические и другие факторы, с которыми может быть сопряжено производство.

3. Точность выбора входящих в (10) параметров может быть существенно повышена путем уточнения статистического значения относительной массы конструкции из табл. 1 и 2 корректировкой ее посредством анализа на уровне структурных групп конструкции самолета, а при необходимости даже на уровне компонентов самих структурных групп (табл. $3-6$ ).

Дальнейшее уточнение прогнозируемых результатов на стадиях общего проектирования самолета, при которых уже известны или могут быть выбраны во втором приближении расчета массы, может быть достигнуто при использовании весовых зависимостей, содержащих многочисленные коэффициенты, учитывающие летно-технические, технологические, компоновочные и другие особенности компоновки, производства, эксплуатации конкретного самолета, приведенные в [12, 13, 17 - 19] и других источниках.

4. Предложенный статистический подход может оказаться эффективным и для других классов летательных аппаратов, в частности вертолетов [20 $22]$ и ракет [23, 24], при наличии или по мере накопления статистического материала по распределению масс по структурным группам разного уровня, аналогичным рассмотренным в табл. $1-6$.

5. Дальнейшая углубленная разработка предложенного статистического подхода может быть положена в основу синтеза научных основ прогнозирования внедрения ПКМ в конструкции летательных аппаратов как краткосрочного, так и перспективного периодов с учетом различных определяющих факторов отечественного развития отрасли.

\section{Литература}

[1] Каблов Е. Н. Материалы для авиакосмической техники / Е. Н. Каблов // Российская энциклопедия CALLS. Авиационно-космическое авиастроение. М.: НИЦ АСК, 2008 - С. $377-388$.

[2] Гришин А. И. Прочность и устойчивость элементов и соединений авиационных конструкций из композитов назначения / А. И. Гришин, А. С. Дзюба, Ю. И. Дударев. - М.: Физматлит, 2013. - 272 с.

[3] Кива Д. С. Этапы становления и начала развернутого применения полимерных композиционных материа- лов в авиаконструкциях отечественного назначения (1970 - 1995 гг.) / Д. С. Кива // Авиационно-космическая техника и технология. - 2014. - № 6(113). C. $5-16$.

[4] Beral B. A-350XWB Structures: A major Step forward for Composite Application / B. Beral // SAMPE EUROPE Techical Conferencef.\& "Table-Top", Exhibition 2008 (SETEC 03/-08), 18-19 September 2008, Augsburg, Germany. - 2008. - P. $124-134$.

[5] COMPOSITE: 21 century. - М.: Издательский дом «Композиты 21 век», 2011. - 64 с.

[6] Daniel I. M. Whiteside. Effects of material and stacking sequence on behavior of composite plates with holes / I. M. Daniel, R. E. Rowlands // Experimental mechanics/ - 1974. -№14. - P. $1-9$.

[7] Anglin J. M. Application of composites in commercial aircraft abound / J. M. Anglin // ICAO Bulletin. Vol. 41. - 1986. - P. $14-17$.

[8] Gay D. Composite Materials. Design and Application / D. Gay, S. V. Hoa. - CRC Press, 2007. - 328 p.

[9] Аверичкин П. А. Методология применения и оценка эффективности использования композиционных материалов в авиационной технике / П. А. Аверичкин. - Ярославль: ЯГСХА, 1999. - 306 с.

[10] Кива Д. С. Научные основы интегрированного проектирования самолетов транспортной категории: моногр. / Д. С. Кива, А. Г. Гребеников. - Х.: Нац. аэрокосм. ун-т им. Н.Е. Жуковского «ХАИ», 2014. Ч. $2 .-326 \mathrm{c}$.

[11] Егер С. М. Основы авиационной техники: учебник / С. М. Егер, А. М. Матвеенко, И.А. Шаталов. - М.: Изд-во МАИ, 1999. - 576 с

[12] Проектирование самолетов: учебник / С. М. Егер, В. Ф. Мишин, Н. К. Лисейцев и др.; под ред. В.Ф. Мишина. - М.: Машиностроение, 1983. - 616 с

[13] Torenbeek E. Synthesis of Subsonic Airplane Design / E. Torenbeek. - Delft University Press, 1982. - 598 p

[14] Михайлин Ю. А. Конструкционные полимерные композиционные материалы / Ю. А. Михайлин. СПб.: Науч. основы и технологии, 2008. - 822 с.

[15] Композиционные материалы: справ. / В. В. Васильев, В. Д. Протасов, В. В. Болотин и др; под общ. ред. В. В. Васильева, Ю. М. Тарнопольского. - М.: Машиностроение, 1990. - 512 с

[16] Композиционные материалы: справ. / под ред. Д. М. Карпиноса. - К. : Наук. думка, 1985. - 592 с.

[17] Шейнин В. М. Весовое проектирование и эффективность пассажирских самолетов / В. М. Шейнин, В. И Козловский. - М.: Машиностроение, 1977. T. $1 .-339$ c.

[18] Шейнин В. М. Весовая и транспортная эффективность пассажирских самолетов / В. М. Шейнин. М.: Оборонгиз, 1962. - 357 с.

[19] Астанін В. В. Композиційні матеріали в конструкціях сучасних літальних апаратів / В. В. Астанін, А. В. Хоменко, О. А. Шевченко // Вісник нац. авіац. ун-та. -2004 . - №3 - С. $46-52$. 
[20] Жустрин Г. К. Весовые характеристики вертолета и их предварительный расчет / Г. К. Жустрин, В. В. Кронштадтов. - М.: Машиностроение, 1978. - 110 с.

[21] Статистические данные зарубежных вертолетов: обзор ЦАГИ. - № 678. - 1988. - 431 с.

[22] Общее проектирование вертолетов / В. А. Богуслаев, В. С. Кривцов, Л. И. Лосев, В. И. Рябков. Запорожье: ОАО «Мотор Сич», 2001. - 324 с.
[23] Дракин И. И. Основы проектирования беспилотных летательных аппаратов с учетом экономической эффективности / И. И. Дракин. - М.: Машиностроение, 1973.- $224 \mathrm{c}$.

[24] Проектування і конструювання ракет-носіїв / В. В. Близниченко, Є. О. Джур, Р. Д. Краснікова та ін.; за ред. С. М. Конюхова. - Дніпропетровськ: Видво ДНУ, 2007. - 504 c.

Gvozdov M.O. ${ }^{1}$, Kondratiev A.V. ${ }^{2}$

${ }^{1}$ ANTONOV, State-owned Enterprise. Ukraine, Kiev

${ }^{2}$ National Aerospace University «Kharkiv Aviation Institute». Ukraine, Kharkiv

\section{PREDICTION OF TECHNICALLY POSSIBLE AMOUNT OF POLYMER COMPOSITE MATERIAL ADOPTION IN AIRCRAFT STRUCTURES}

General statistical approach to prediction of technically possible amount of polymer composite material adoption in aircraft structures is suggested further in-depth development of statistical approach suggested can be used as fundamentals of principles of scientific synthesis of prediction of technically possible amount of polymer composite material adoption in both short- and long-term aircraft structures with different domestic industry branch determinative factors taken into account.

Keywords: aircraft; polymer composite materials; forecasting; statistical approach.

\section{References}

[1] Kablov E. N. Materials for aviation and space equipment [Materialy dlya aviakosmicheskoi tehniki] / E. N. Kablov // Russian Encyclopedia CALLS. Aerospace aircraft. - Moscow: Research Center of the automated systems of designing, 2008 - P. 377 - 388.

[2] Grishin A. I. The strength and stability of elements and compounds of composite aircraft structures destination [Prochnost i ustoichivost elementov i soedinenii aviacionnyh konstrukcii iz kompozitov naznacheniya]. A.I. Grishin, A. S. Dzyuba, Yu. I. Dudarev. - Moscow: Fizmatlit, 2013. - 272 p.

[3] Kiva D. S. Stages of formation and beginning of expand use of polymer composite materials in aviation constructions for domestic purposes (1970 - 1995 years) [Etapy stanovleniya i nachala razvernutogo primeneniya polimernyh kompozicionnyh materialov v aviakonstrukciyah otechestvennogo naznacheniya (1970 - 1995 gg.)] / D. S. Kiva // Aerospace Engineering and Technology. - 2014. - № 6(113). - P. 5 - 16.

[4] Beral B. A-350XWB Structures: A major Step forward for Composite Application / B. Beral // SAMPE EUROPE Techical Conferencef.\&“Table-Top”, Exhibition 2008 (SETEC 03/-08), 18-19 September 2008, Augsburg, Germany. 2008. - P. $124-134$.

[5] COMPOSITE: 21 century. - Moscow: Publishing house "Composites 21 century", 2011. - 64 p.

[6] Daniel I. M. Whiteside. Effects of material and stacking sequence on behavior of composite plates with holes / I. M. Daniel, R. E. Rowlands // Experimental mechanics/ - 1974. -№14. - P. 1 - 9.

[7] Anglin J. M. Application of composites in commercial aircraft abound / J. M. Anglin // ICAO Bulletin. -Vol. 41. - 1986. - P. $14-17$.

[8] Gay D. Composite Materials. Design and Application / D. Gay, S. V. Hoa. - CRC Press, 2007. - 328 p.

[9] Averichkin P. A. The methodology of the application and evaluation of the use of composite materials in aircraft engineering [Metodologiya primeneniya i ocenka effektivnosti ispolzovaniya kompozicionnyh materialov $\mathrm{v}$ aviacionnoi tehnike / P. A. Averichkin. - Yaroslavl: Yaroslavl State Agricultural Academy, 1999. - 306 p.

[10] Kiva D. S. Scientific bases of integrated design of transport category airplanes [Nauchnye osnovy integrirovannogo proektirovaniya samoletov transportnoi kategorii: monograph / D. S. Kiva, A. G. Grebenikov. - Kharkiv.: National Aerospace University «Kharkiv Aviation Institute», 2014. - Part. 2. - 326 p. 
[11] Eger S. M. Basics of aeronautical engineering [Osnovy aviacionnoi tehniki]: textbook / S. M. Eger, A. M. Matveenko, I. A. Shatalov. - Moscow: Publisher Moscow Aviation Institute, 1999. - 576 p

[12] Aircraft design [Proektirovanie samoletov]: textbook / S. M. Eger, V. F. Mishin, N. K. Liseicev and others; edited by V. F. Mishin. - Moscow: Mashinostroenie, 1983. - 616 p.

[13] Torenbeek E. Synthesis of Subsonic Airplane Design / E. Torenbeek. - Delft University Press, 1982. - 598 p

[14] Mihailin Yu. A. Structural polymer composite materials [Konstrukcionnye polimernye kompozicionnye materialy] / Yu. A. Mihailin. - St. Petersburg: Scientific basis and technology, 2008. - 822 p.

[15] Composite Materials [Kompozicionnye materialy]: handbook / V. V. Vasiliev, V. D. Protasov, V. V. Bolotin and others; edited by V. V. Vasiliev, Yu. M. Tarnopoliskii. - Moscow: Mashinostroenie, 1990. - 512 p.

[16] Composite Materials [Kompozicionnye materialy]: handbook / edited by D. M. Karpinos. - Kiev: aukova dumka, 1985. - 592 p.

[17] Sheinin V. M. Weight design and efficiency of passenger aircraft [Vesovoe proektirovanie i effektivnost passazhirskih samoletov] / V. M. Sheinin, V. I Kozlovskii. - Moscow: Mashinostroenie, 1977. - Vol. 1. - 339 p

[18] Sheinin V. M. Weight and transport performance of passenger aircraft [Vesovaya i transportnaya effektivnost passazhirskih samoletov] / V. M. Sheinin. - Moscow: Oborongiz, 1962. - 357 p.

[19] Astanin V. V. Composite materials in the construction of modern aircraft [Kompoziciyni materiali v konstrukciyah suchasnih litalynih aparativ] / V. V. Astanin, A. V. Homenko, O. A. Shevchenko // Journal of National Aviation University. - 2004 - №3- P. $46-52$.

[20] Zhustrin G. K. The weight of the helicopter and their preliminary calculation [Vesovye harakteristiki vertoleta i ih predvaritelynyi raschet] / G. K. Zhustrin, V. V. Kronshtadtov. - Moscow: Mashinostroenie, 1978. - 110 p.

[21] The statistical data of foreign helicopters: overview Central Aero-Hydrodynamic Institute. - №678 - 1988.

[22] The general design of helicopters [Obshee proektirovanie vertoletov / V. A. Boguslayev, V. S. Kryvtsov, L. I. Losev, V. I. Ryabkov. - Zaporozhye: Motor Sich JSC, 2001. - 324 c.

[23] Drakin I. I. Basics of designing unmanned aerial vehicles, taking into account economic efficiency [Osnovy proektirovaniya bespilotnyh letatelynyh apparatov s uchetom ekonomicheskoi effektivnosti] / I. I. Drakin. - Moscow: Mashinostroenie,, 1973.- 224 p.

[24] Designing and constructing launch vehicles [Proektuvannya i konstruyuvannya raket-nosiiv]/ V. V. Bliznichenko, E. O. Dzhur, R. D. Krasnikova and others; edited by S. M. Konyukhov. - Dnipropetrovsk: Publishing of Dnipropetrovsk National University, 2007. - 504 c. 